
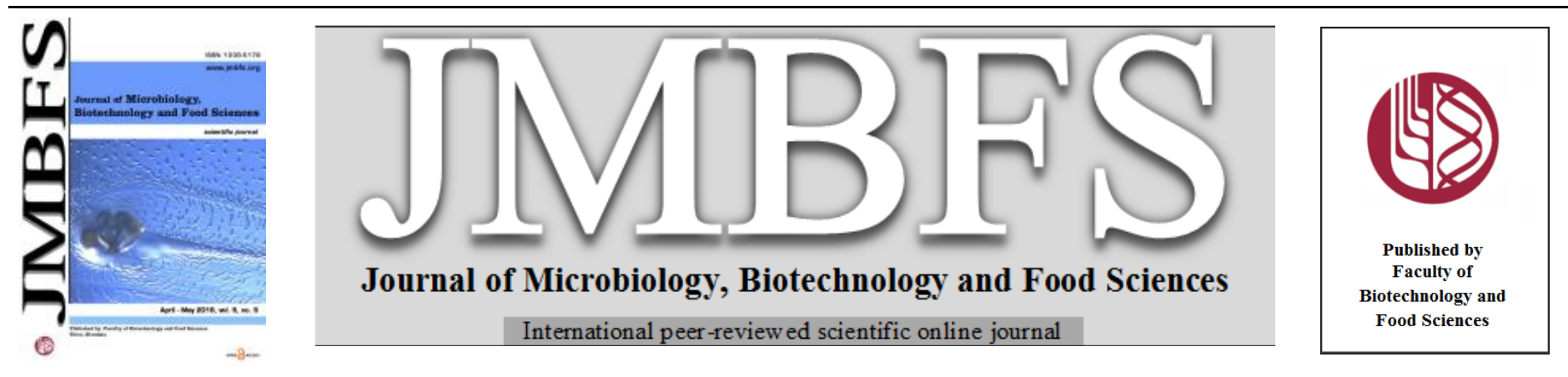

\title{
THE DIAGNOSIS AND EFFECT OF BREAST TUMORS TREATMENT IN DOGS
}

\section{Narziev Baxtiyor and Yulchyiev Jasurbek}

Address(es): Yulchyiev Jasurbek,

Samarkand Agricultural Institute, Veterinary Medicine Faculty, Mirzo Ulugbek 77, Samarkand, Uzbekistan, +998662343320.

*Corresponding author: jasur_vet@mail.ru

doi: $10.15414 / j m b f s .2016 .5 .5 .475-477$

\section{ARTICLE INFO}

Received 15. 12. 2015

Revised 6. 1. 2016

Accepted 13. 1.2016

Published 1. 4. 2016

Regular article

open $\bigodot_{\text {ACCESS }}$

\begin{abstract}
This study reports the spread of tumors of mammary gland in dogs. Changes in blood immunological and morphological parameters of affected dogs are presented. Results of immunotherapy used for activation of immune system after surgery showed various level of stimulation. Application of levamisole increase the percentage of $\mathrm{T}$ - and B-lymphocytes as well as the ratio of normalized subpopulations of $\mathrm{T}$ lymphocytes (T-helper and T-suppressor cells) indicating potential effect of levamisole. Application of BCG improved performance of $\mathrm{T}$ - and B-lymphocytes, but in comparison with the effect of levamisole some imbalance between subpopulations of T-helper and T-suppressor cells was detected. In the control group (simple tumor removal) different results were found indicating immunosuppressive effect of tumors.
\end{abstract}

Keywords: tumor, immunity, lymphocytes, therapy

\section{INTRODUCTION}

In recent years a significant development occurs in the study of cancer diseases in animals and especially in dogs. The reasons that lead to the appearance of tumors in dogs are (1) those associated with the occurrence of tumors in farm animals, often worn by the character of widespread, requiring the adoption of appropriate measures, based on scientific research, and (2) increased interest in problems comparing tumors in humans and domestic animals, as the latter the "model" in the study of human tumors and significant role in the expansion of knowledge about the nature of tumor growth providing appropriate care in the treatment of tumor development (Gardner et al., 2015). It should be noted that according to the scientific and experimental studies, dogs have the same sensitivity to carcinogens as gas pollution, ionizing radiation, solar radiation etc. Furthermore, tumors in dogs develop after the start of exposure to carcinogens much faster than in man. With this in mind, as well as the fact that dogs live in the same environment, and often eat the same food, drink the same water as the man a study of tumors for early detection of possible human carcinogen environmental factors is quite urgent. Identifying similarities in development of certain tumors in dogs and humans can be considered as natural models and can be used for study of the development of human tumor, their diagnosis and the development of new treatments. Finally methods of diagnosis and treatment of tumors in humans may be used in relation to tumors in dogs (Regan et al., 2015; Weisse 2015).

The most common types of cancer in dogs are tumors of the breast. Mammary gland tumors in dogs range from 25 to $41 \%$ of all neoplasia (Horn and Horn 1971; Terekhov, 1983; Melief 2000; Artamonova, 2002; Chalyiuv et al., 2002; Chagpar et al., 2004; Haberkorn et al., 2013). According to several authors (Terekhov 1983; Artamonova 2002; Gonzalez-Angulo_et al., 2007) mammary tumors in dogs has an impact on the weight of the body, including the immunity. The problem of immunological reactivity in tumor growth remains one of the most important scientific problems of modern medicine and veterinary medicine.

The promise of pharmaceutical biotechnology and its applications to health care is now being realized. Therapeutic agents produced by the tools of biotechnology are now available. Recombinant proteins, monoclonal antibodies, gene therapy, and vaccines can provide effective treatments and cures for diseases we could only mitigate in the past. The availability of these drugs presents several interesting challenges and opportunities to pharmacists. The expense, complexity, and unique properties of biotechnology agents will continue to alter not only the knowledge base of pharmacy but also the way pharmacists perform their professional responsibilities (Piascik, 1998).

Aim of study was to analyze the effect of levamisole and BCG on selected immunological and hematological parameters in dogs with cancer pathologies.

\section{MATERIAL AND METHODS}

In this study dogs with tumors of the breast, received at the Department of Anatomy, Physiology, Surgery and Pharmacology of Animals, Samarkand Agricultural Institute were analyzed. From 150 dogs examined breast tumor of various sizes was detected in 45 cases. Dogs were divided into 3 groups: 2 experimental and control.

All dogs were subjected to surgical intervention to remove breast cancer. In the first experimental group (E1) dogs received levamisole (intramuscular $75 \mathrm{mg}$ two injections a week); in the second experimental group (E2) Bacillus CalmetteGuerin (BCG, subcutaneously $0.5 \mathrm{mg}$ once per week). The third group served as a control in which only the surgical removal of the tumor was realized.

For general anesthesia i.v. $2.5 \%$ solution of chlorpromazine $(1 \mathrm{ml}$ per $10 \mathrm{~kg}$ body weight), $5 \%$ ketamine $(1 \mathrm{ml})$, and in some cases for complete relaxation intramuscular injection of $2 \%$ xyla $(0.15 \mathrm{ml}$ per $10 \mathrm{~kg}$ body weight $)$ was used. For local anesthesia $0.5 \%$ novocain solution was used, injected between the skin and the capsule of the tumor.

After each injection the blood was analyzed for hemoglobin, erythrocytes, leukocytes and leukocyte formula by conventional methods, T- and Blymphocytes were determined by plaque assay. Diagnosis was based on clinical and histological studies. Clinical examination included an assessment of the primary tumor sites, regional lymph nodes, and the general condition of the animal.

\section{RESULTS AND DISCUSSION}

For removing the breast tumor straight-line or spindle-shaped incision was used, depending on the size of the tumor. After making the skin incision blunt was capable for skin separation from the tumor capsule. It was necessary to stop the bleeding during the operation mechanically. After removal of the breast tumor performed skin grafting was done and interrupted skin sutures were applied. In cases of metastasis in the regional lymph nodes they were also removed. Sutures were removed on day 7-10.

In the first group (E1) with levamisole application the level of T-lymphocytes before the therapy was $38.3 \pm 2.6 \%$ after the applications $53.3 \pm 0.3 \%$ of white blood cells $(277.4 \pm 0.6$ vs. $1271.5 \pm 0.8$ per $\mu 1)$. The level of B-lymphocytes was before therapy $4.3 \pm 0.3 \%$ and after the therapy reached $15.7 \pm 1.0 \%(31.6 \pm 0.8 \mathrm{vs}$. $374.2 \pm 1.5$ per $\mu 1)$. For subpopulation of T-lymphocytes the relative occurrence of T-helper cells was $26.6 \pm 1.6 \%$ vs. $36.3 \pm 1.6 \%$ and T-suppressors $7.6 \pm 0.1 \%$ vs $8.0 \pm 0.6 \%$ after therapy (Figure 1). 


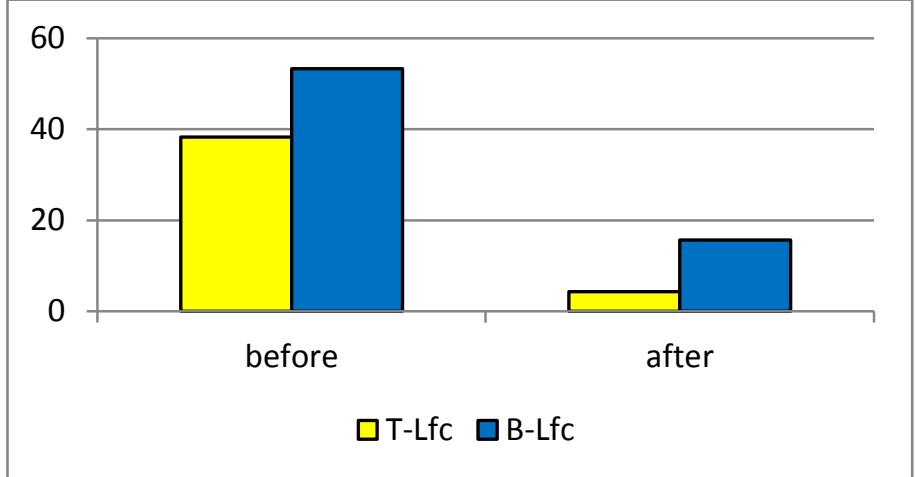

Figure 1 Percentage (\%) of T- and B-lymphocyte of white blood cells in the group E1 - levamisole application

In the second group (E2) the BCG immunotherapy was conducted once a week The relative amount of T-lymphocytes prior to application was $38.6 \pm 1.3 \%$ and after application $53.6 \pm 3.0 \%$ (552.9 \pm 2.9 vs. $2702.0 \pm 7.5$ per $\mu 1)$. The number of Blymphocytes increased from $5.6 \pm 1.0 \%$ to $18.0 \pm 0.6 \%$ ( $83.0 \pm 4.0$ vs. $915.3 \pm 2.7$ per $\mu 1)$. In the study of subpopulations of T-lymphocytes the level of T-helper cells increased from $27.0 \pm 0.7 \%$ to $38.6 \pm 2.3 \%$ and T-suppressor cells from $8.3 \pm 0.6 \%$ to $17.6 \pm 0.9 \%$. BCG stimulated the immune system with clear increase of the levels of T-lymphocytes and their subpopulations (Figure 2).

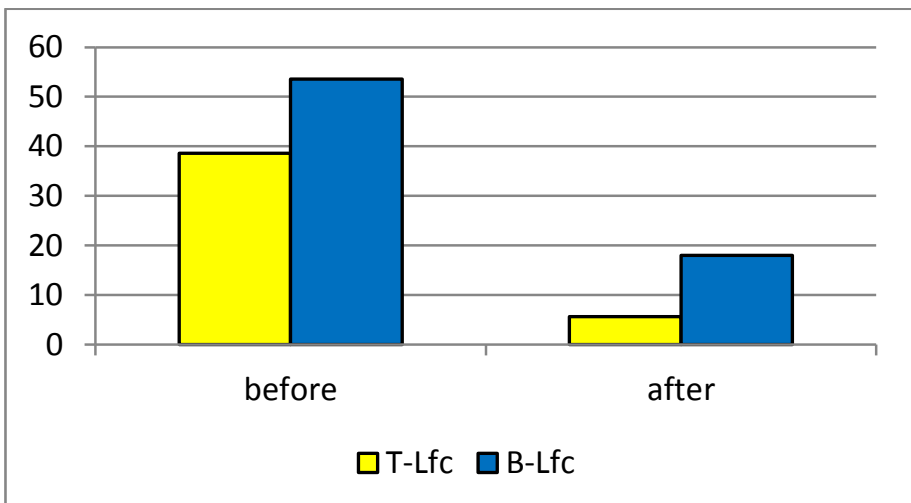

Figure 2 Percentage $(\%)$ of T- and B-lymphocyte of white blood cells in the group E2 - BCG application

In the control group (surgical intervention) results were different (Figure 3). A decrease of the relative level of T-lymphocytes was found $-40.6 \pm 2.6 \% \mathrm{vs}$. $34.0 \pm 1.3 \%$ ( $376.7 \pm 0.7$ vs. $233.0 \pm 1.0$ per $\mu 1$ ). The percentage of B-lymphocytes was $9.0 \pm 2.0$ vs. $8.6 \pm 2.3 \%(83.1 \pm 2.0$ vs. $58.3 \pm 1.6$ per $\mu 1)$. In the subpopulation of lymphocytes T-helper cells decreased from $26.3 \pm 0.3 \%$ to $23.0 \pm 3.0 \%$ with simultaneous increase of T-suppressor from $12.6 \pm 0.8 \%$ to $18.3 \pm 2.6 \%$.

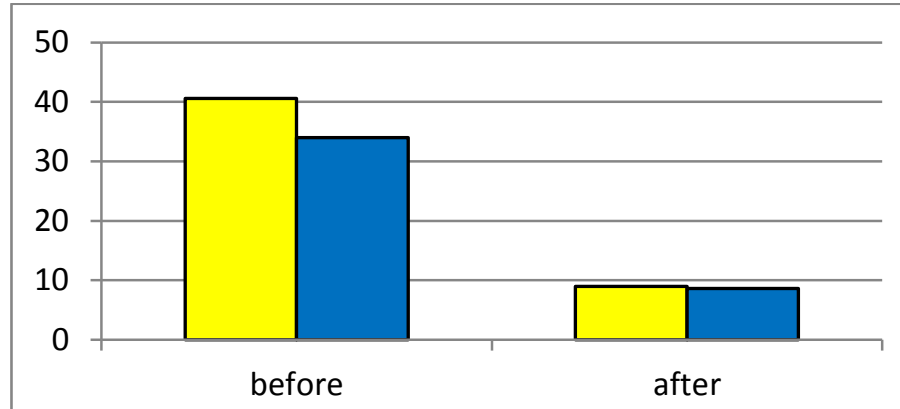

$\square T$-LfC $\square B-L f C$

Figure 3 Percentage (\%) of T- and B-lymphocyte of white blood cells in the control group - only the surgical removal of the tumor

Generally cancer suppresses the immune system. In the investigation of immunotherapy to blood in dogs a decrease of lymphocyte to 6-8\% was observed. After removal of tumors in dogs the immune system was stimulated in groups with BCG and levamisole application.

Cytological or histological examination of tissue is usually used for tumor identification. Instrumental methods as X-ray or ultrasound are used to find distant nodal or hematogenous metastases. Clinical signs of breast cancer are paraneoplastical syndromes (Piane $\boldsymbol{e t}$ al., 2014), which usually do not develop immediately and strongly time lag in the development of the visible changes of the breast configuration. Deformation can form single or multiple units of various sizes, texture, density, with or without cysts affecting one or more packets of the breast, often painful, but sometimes accompanied by pain and signs of inflammation with broken or intact skin over the deformation (Lim et al., 2015). Morphological (cytological and histological) diagnosis of tumors of the mammary glands is required for the following tasks - differential diagnosis of breast tumors from benign diseases, identification of breast cancer to develop tactics for further diagnostic and therapeutic measures, determination of the histological characteristics of the tumor (type, germination of the capsule, the degree of malignancy) for the development of operational tactics after the treatment and control of metastasis and prognosis of outcomes, morphologica study of regional lymph nodes for detection of nodal metastases as well as cytology performed to detect cancer cells by aspiration or biopsy (Munson and Moresco, 2007; Klopfleisch et al., 2011).

Immuno-biological studies of the interaction of organisms with tumor cells and tissues show that the determining factor in the prevention of the emergence and development in the effective elimination of tumor cells is the stimulation of both specific and non-specific defense systems of the body and immune system as a whole (Eifel et al. 2001).

It is also known that the most important are the problems of cancer therapy. It was found that many drugs and methods for treating tumors give quite good results, even in the treatment of experimental tumors were unsuitable or quite effective in the treatment of spontaneous animal and human tumors. That is why the use of affected animals with spontaneously occurring tumors seems more promising to clarify many issues genesis blastoma process research to develop effective treatments for tumors of humans and animals (Terekhov, 1983; Melief 2000; Chalyiuv et al. 2002)

The most effective treatment is the biophysical and/or biochemical processes against pathological processes that lead to disease. However, the study of the phenomenon known as "the body's resistance" is the first step. Significant theoretical advance in oncology was the discovery that cancer is caused by a specific immune response in the body, in which it appears (Brtitta et al., 2005; Haberkorn et al., 2013).

Many growing tumors suppress the body immunity. Immunosuppressive effect is particularly evident in the advanced stage of cancer (also tumors of small size). There is little doubt that the immune response plays an important role in the growth and development of tumors (Melief et al., 2000; Luzhna et al., 2013; Artamonova et al., 2002). According to animals in which malignancy is caused by a virus the immune system is suppressed. First, cell-mediated immunity is suppressed, directly or indirectly related to the effect of the virus on lymphoma cells. The result is a total suppression of the immune system in the process of formation and growth of tumors (Chalyiuv et al., 2002; Haberkorn et al., 2013) The actual problem of the trends in the treatment of oncological pathologies is the immunotherapy and enhancing immune reactivity (Terekhov, 1983; Artamonova et al., 2002; Haberkorn et al., 2013). Immunotherapy is a treatment of disease by active and passive immunization. The task is to find effective immunization of the patient against the tumor as described also in this study.

\section{CONCLUSION}

Cancer markedly declines the immune status of the body, reducing the rate and quantitative level of T-lymphocytes, with the predominance of suppressor activity of helper. Application of levamisole increase the percentage of T- and Blymphocytes as well as the ratio of normalized subpopulations of T lymphocytes (T-helper and T-suppressor cells) indicating potential effect of levamisole. Application of BCG improved performance of T- and B-lymphocytes, but in comparison with the effect of levamisole some imbalance between subpopulations of T-helper and T-suppressor cells was detected. In the control group different results were found indicating immunosuppressive effect of tumors.

\section{REFERENCES}

ARTAMONOVA, E.V., TUPITSYN, N.N., KADAGIDZE, Z.G., LETIAGIN, V.P, ERMILOVA, V.D., OGNERUBOV, N.A., PANICHENKO, A.V. RIAZANTSEVA, S.N. 2002. The role of epithelial antigens in diagnosis and staging of breast cancer. Arkhiv Patologii, 64(6), 13-15.

BRITTA, W., JOHANNES, L., PETERSE, L., VAN'T VEER, J. 2005. Breas cancer metastasis: Markers and models. Nature Reviews Cancer, 5, 591-602. http://doi:10.1038/nrc1670

CHALYI, I.V., KOLESNIKOVA, T.S., FEGEDING, K.V., VOITENOK, N.N., 2002. Effect of tumor necrosis factor-alpha on synthesis of interleukin- 8 by human monocytes and lymphocytes in vitro. Byulleten Eksperimental'noi Biologii i Meditsiny, 122(8), 200-202.

EIFEL, P., AXELSON, J.A., COSTA, J., CROWLEY, J., CURRAN, W.J.JR., DESHLER, A., FULTON, S., HENDRICKS, C.B., KEMENY, M., KORNBLITH, A.B., LOUIS, T.A., MARKMAN, M., MAYER, R., ROTER, D. 
2011. National institutes of health consensus development conference statement: Adjuvant therapy for breast cancer. Journal of National Cancer Institute, 93(13), 979-989. http://doi:10.1093/jnci/93.13.979

CHAGPAR, A., LANGSTEIN, H.N., KRONOWITZ, S.J., SINGLETARY, S.E., ROSS, M.I., BUCHHOLZ, T.A., HUNT, K.K., KUERER,.H.M. 2004. Treatment and outcome of patients with chest wall recurrence after mastectomy and breast reconstruction. American Journal of Surgery, 187(2), 164-169. http://dx.doi.org/10.1016/j.amjsurg.2003.11.006

GARDNER, H.L., FENGER, J.M., LONDON, C.A. 2015. Dogs as a Model for Cancer. Annual Review of Animal Bioscience, in press. http://doi:10.1146/annurev-animal-022114-110911

GONZALEZ-ANGULO, A.M., MORALES-VASQUEZ, F., HORTOBAGYI,

G.N. 2007. Overview of resistance to systemic therapy in patients with breast cancer. Advanced Experimental Medicine and Biology, 608, 1-22.

HABERKORN, J., BURBAUM, C., FRITZSCHE, K., GESER, W., FUCHS, D., OCAÑA-PEINADO, F.M., SCHUBERT, C. 2013. Day-to-day cause-effect relations between cellular immune activity, fatigue and mood in a patient with prior breast cancer and current cancer-related fatigue and depression. Psychoneuroendocrinology, 38(10), 2366-2372. http://doi:10.1016/j.psyneuen.2013.03.001

HORN, L., HORN, H. 1971. An immunological approach to the therapy of cancer. Lancet, 298 (7722), 466-470. http://dx.doi.org/10.1016/S01406736(71)92632-8

KLOPFLEISCH, R., VON EULER, H., SARLI, G., PINHO, S.S., GÄRTNER, F., GRUBER, A.D. 2011. Molecular carcinogenesis of canine mammary tumors: news from an old disease. Veterinary Pathology, 48(1), 98-116. http://doi:10.1177/0300985810390826

LIM, H.Y., KIM, K.S., KIM, N.H., KIM, H.W., SHIN, J.I., SUR, J.H. 2015. Obesity, expression of adipocytokines, and macrophage infiltration in canine mammary tumors. Veterinary Journal, 203(3), 326-331. http://doi:10.1016/j.tvj1.2015.01.005

LUZHNA, L., GOLUBOV, A., ILNYTSKYY, S., CHEKHUN, V.F., KOVALCHUK, O. 2013. Molecular mechanisms of radiation resistance in doxorubicin-resistant breast adenocarcinoma cells. International Journal of Oncology, 42(5), 1692-1708. http://doi:10.3892/ijo.2013.1845

MELIEF, C.J., TOES, R.E., MEDEMA, J.P., VAN DER BURG, S.H., OSSENDORP, F., OFFRINGA, R. 2000. Strategies for immunotherapy of cancer. Advances in Immunology. 75, 235-282.

MUNSON. L, MORESCO, A. 2007. Comparative pathology of mammary gland cancers in domestic and wild animals. Breast Diseases, 28, 7-21

PIANE, L., SAYAG, D., LERMUZEAUX, J., SEMIN, M.O., LAMOURLAYSSOL, C., AUMANN, M., TRUMEL, C. 2014. What is your diagnosis? Abnormal cells on a blood smear from a dog. Veterinary and Clinical Pathology, 43(3), 461-462. http://doi:10.1111/vcp.12159

PIASCIK, P. 1998 Biotechnology: An overview of the tools, therapeutic agents, and applications to pharmacy practice. Pharmacy Practice Management Quarterly, 18(2), 1-12.

REGAN, D., GUTH, A., COY, J., DOW, S. 2015. Cancer immunotherapy in veterinary medicine: Current options and new developments. Veterinary Journal, in press. http://doi:10.1016/j.tvj1.2015.10.008

TEREKHOV, P.F. 1983. "Veterinary Oncology. Moscow, 555 p.

WEISSE, C. 2015. Veterinary interventional oncology: from concept to clinic

Veterinary Journal, 205(2), 198-203. http://doi:10.1016/j.tvjl.2015.03.027 